Article

\title{
Preparation and Characterization of In Situ Carbide Particle Reinforced Fe-Based Gradient Materials by Laser Melt Deposition
}

\author{
Weian Zong ${ }^{1}$, Song Zhang ${ }^{1, *(\mathbb{D}, \text { Chunhua Zhang }}{ }^{1}$, Chenliang $\mathrm{Wu}^{1}{ }^{1}$, Jingbo Zhang ${ }^{2}$, Yu Liu ${ }^{2}$ \\ and Adil O. Abdullah ${ }^{3}$ (D) \\ 1 School of Materials Science and Engineering, Shenyang University of Technology, \\ Shenyang 110870, Liaoning, China \\ 2 Shenyang Dalu Laser Technology CO., LTD, Shenyang 110136, Liaoning, China \\ 3 Stomatology Research Center, School of Stomatology, China Medical University, \\ Shenyang 110002, Liaoning, China \\ * Correspondence: songzhang_sy@sut.edu.cn; Tel.: +86-134-7889-9886
}

Received: 18 June 2019; Accepted: 23 July 2019; Published: 25 July 2019

\begin{abstract}
To obtain the wear-resistant camshaft with surface rigidity and core toughness and improve the service life of camshaft, wear-resistant Fe-based alloy gradient material was prepared by laser melt deposition. The traditional camshaft was forged by $12 \mathrm{CrNi} 2 \mathrm{~V}$. In this paper, four types of wear-resistant Fe-based powders were designed by introducing various content of $\mathrm{Cr}_{3} \mathrm{C}_{2}$ and V-rich Fe-based alloy (FeV50) into stainless steel powder. The results showed that the gradient materials formed a satisfactory metallurgical bond. The composition of the phases was mainly composed of $\alpha-\mathrm{Fe}, \mathrm{Cr}_{23} \mathrm{C}_{6}$, and $\mathrm{V}_{2} \mathrm{C}$ phases. The increasing of $\mathrm{Cr}_{3} \mathrm{C}_{2}$ and $\mathrm{FeV} 50$ led to transform $\mathrm{V}_{2} \mathrm{C}$ into the $\mathrm{V}_{8} \mathrm{C}_{7}$. The microstructures were mainly cellular dendrite and intergranular structure. Due to the addition of $\mathrm{Cr}_{3} \mathrm{C}_{2}$ and $\mathrm{FeV} 50$, the average microhardness and wear resistance of gradient materials were significantly better than that of $12 \mathrm{CrNi2}$. The sample with $8 \% \mathrm{~V}$ had the highest microhardness of $853 \pm 18 \mathrm{HV}$, which was 2.6 times higher than that of $12 \mathrm{CrNi2V}$. The sample with $6 \% \mathrm{~V}$ had the best wear resistance, which was 21 times greater than that of $12 \mathrm{CrNi} 2 \mathrm{~V}$.
\end{abstract}

Keywords: laser melt deposition; Fe-based gradient materials; wear resistance; in situ synthesis

\section{Introduction}

As one of the core components of the diesel engine, the camshaft faces many challenges in terms of quality [1]. The 12CrNi2V low alloy steel was a common material for manufacturing the camshaft $[2,3]$. The shape and structure of the camshaft was complex, as shown in Figure 1. Due to the special working condition of the camshaft, the surface of the camshaft is required to have certain rigidity and wear resistance, and the core has toughness, but the traditional carburizing and quenching cannot meet the service requirement [4]. The laser melt deposition (LMD, also known as laser cladding) technology and the functionally graded material (FGM) provided a new technical support for the preparation of the camshaft, and simultaneously met the performance requirements of the camshaft and the requirements of energy conservation and emission reduction [5].

FGMs have been widely studied for their excellent mechanical properties [6-8]. FGMs have different properties on both sides of the similar material, which fully met the requirements of camshaft surface rigidity and core toughness. At present, the main preparation methods of FGM are powder metallurgy [9], plasma spraying [10], self-propagating high-temperature synthesis [11], and spray deposition [12]. Ren et al. [13] prepared Ti-6Al4V/Ti-6.5Al-3.5Mo-1.5Zr-0.3Si gradient materials by LMD. It was found that there were columnar grains in Ti-6Al-4V and Ti-6.5Al-3.5Mo-1.5Zr-0.3Si parts. 
The chemical composition of the gradient region was characterized by step, and the height of the step decreased with the increase of the deposited layer. The microhardness of the gradient region varied with the change of chemical composition. The gradient materials had acceptable metallurgical bonding and room temperature tensile properties. Gualtieri et al. [14] studied the additive manufacturing of gradient metal-ceramic structures. The microhardness and wear resistance of the coatings were greatly improved by the internal stress of the carbides. The composite gradient coating was formed by depositing $100 \%$ of Vanadium carbide (VC), resulting in smaller and more uniform grains. The VC acted to strengthen the particles and improve the microhardness and wear resistance. The wear rate of the coatings decreased significantly with the addition of the VC.

As an advanced laser surface engineering, LMD has been studied by many researchers [15-17]. LMD technology can be implemented to achieve near net shape parts with compact structure and satisfied comprehensive properties in a short period even with complex geometric configuration. It has been successfully applied to the direct prototyping of high-performance complex parts and the high-quality repair of high-value parts $[18,19]$. In contrast to the traditional manufacturing process, LMD technology has the advantages of low manufacturing cost, short production cycle, high precision, integrated forming, unrestricted product shape, and less pollution [3]. The composition gradient region could be designed and prepared conveniently by melting metal powder with different volume fraction or powder feeding rate [20]. The combination of the two technologies has been widely concerned and studied by material scientists. Zhang et al. [21] studied the microstructure, phase detection, and microhardness of stainless steel gradient materials prepared by LMD. The results showed that the microstructure of the deposited state was mainly composed of columnar dendrite, and the microstructure changed from columnar dendrite to equiaxed grain with the decrease of $G / R$ ratio during solidification. Due to the high content of $\mathrm{Cr}$ in the alloy powder, it was easy to form $(\mathrm{Cr}, \mathrm{Fe})_{7} \mathrm{C}_{3}$ carbide reinforcing phase, thus the increase of material hardness was observed. The microhardness of the gradient material varies with the change of the composition. Li et al. [22] prepared Ti-6Al-4V to SS316 functionally gradient materials by LMD. The intermetallic phases were not found at the boundary of different adjacent layers. There were ferrite and austenitic phases at the $\mathrm{Cr} / \mathrm{Fe}$ interface. The microhardness gradients were not step, and there was no hard and brittle zone in the structure of the gradient materials. Liu et al. [23] studied the effect of dilution of $\mathrm{Al}$ and $\mathrm{V}$ on the deposition of Ti/Ti6Al4V gradient materials by laser powder. The results showed that the high dilution ratio not only makes the powder and matrix fully mixed, but also contributes to the homogenization of solidification microstructure. $\mathrm{V}$ and $\mathrm{Al}$ content transition from Ti to Ti6Al4V. The microhardness and elastic modulus obtained by nanoindentation tests increased gradually from Ti substrate to Ti6Al4V.

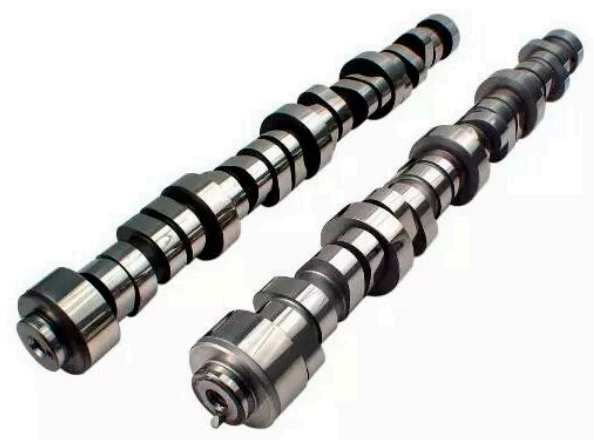

Figure 1. Image of the industrial camshaft.

In this paper, four types of powder with various contents of $\mathrm{Cr}_{3} \mathrm{C}_{2}$ and $\mathrm{FeV} 50$ were designed to improve the wear resistance of a camshaft surface. To obtain a camshaft with surface rigidity and core toughness, Fe-based gradient materials were prepared by LMD technology using $12 \mathrm{CrNi2} \mathrm{V}$ low alloy steel powder and four types of powder. The constituent phase, microstructure, microhardness, and wear resistance were studied. 


\section{Experimental Procedures}

An as-received 35CrMo alloy steel in the form of a plate with a diameter of $150 \mathrm{~mm}$ and the thickness of $15 \mathrm{~mm}$ was used as the substrate material, with the nominal composition in wt. \%: 0.30-0.40 C, $0.17-0.37 \mathrm{Si}, 0.40-0.70 \mathrm{Mn}, 0.80-1.1 \mathrm{Cr}, 0.15-0.25 \mathrm{Mo}$ and balance Fe. The wear-resistant Fe-based alloy powder was prepared by mixing stainless steel, $\mathrm{FeV} 50$, and $\mathrm{Cr}_{3} \mathrm{C}_{2}$ powders with ball milling. The planetary milling machine was used in the experiment. The mixed powder was placed in a ball milling according to a certain mass ratio, and the milling medium was agate ball with a diameter of $10 \mathrm{~mm}$. In addition, the following main milling parameters were set: the ratio of the ball to powder was 10:1, the milling speed was $300 \mathrm{r} / \mathrm{min}$, and the milling time was $2 \mathrm{~h}$. The nominal composition in wt. \% of FeV50 was: $49-52 \mathrm{~V},<4$ trace elements and balance Fe. The chemical compositions of stainless steel powder and wear-resistant Fe-based alloy powder are shown in Tables 1 and 2, respectively. The wear-resistant Fe-based gradient materials were prepared by LMD using the powder P1, P2, P3, and P4 with 12CrNi2V low alloy steel powder, and labelled as S1, S2, S3, and S4, respectively. The nominal composition in wt. \% of $12 \mathrm{CrNi2V}$ low alloy powder was $0.1 \mathrm{C}, 1.5 \mathrm{Cr}, 2.0 \mathrm{Ni}, 0.5 \mathrm{Mn}, 0.5-0.6 \mathrm{Mo}, 1.0-1.2 \mathrm{Si}, 0.5-0.6 \mathrm{~V}, \leq 0.5 \mathrm{~B}$, $\leq 0.5$ trace elements and balance Fe. The alloy powders were dried for $12 \mathrm{~h}$ in a vacuum furnace at $80^{\circ} \mathrm{C}$, and the oxide scale of the substrate was removed before LMD. The gradient materials were prepared using an Ytterbium Laser System equipped with a YLS-6000 fiber laser (a wavelength of $1070 \mathrm{~nm}$ and maximum output power of $6 \mathrm{~kW}$, IPG Photonics, Beijing, China). Within a range of optimization runs, the processing parameters were determined as listed in Table 3. In this paper, gradient materials were prepared by powder feeding. The $12 \mathrm{CrNi} 2 \mathrm{~V}$ powder was deposited layer by layer, and the display screen displayed the current deposition height. When the deposition height reached $6 \mathrm{~mm}$, the wear-resistant Fe-based alloy powder designed in this paper continued to be deposited layer by layer. When the height of the deposited sample reached $12 \mathrm{~mm}$, the Fe-based gradient material was obtained. The schematic of laser melting deposition process is shown in Figure 2. Under these conditions, the deposition heights of $12 \mathrm{CrNi2}$ V low alloy steel and wear-resistant Fe-based alloy were $6 \mathrm{~mm}$, respectively. The final dimension of gradient materials is about $40 \mathrm{~mm} \times 30 \mathrm{~mm} \times 12 \mathrm{~mm}$.

Table 1. Chemical composition of homemade stainless steel powder (wt. \%).

\begin{tabular}{ccccccccc}
\hline $\mathbf{C}$ & $\mathbf{C r}$ & $\mathbf{S i}$ & $\mathbf{N i}$ & $\mathbf{M n}$ & Mo & B & Trace Elements & Fe \\
\hline$\leq 0.18$ & 16.5 & 1.15 & 1.7 & $\leq 0.5$ & 1 & 1.25 & $\leq 0.5$ & Bal. \\
\hline
\end{tabular}

Table 2. Composition designing of alloy powders for different $\mathrm{Cr}_{3} \mathrm{C}_{2}$ and FeV50 content (wt. \%).

\begin{tabular}{cccccccccc}
\hline Powder Number & C & Cr & Si & Ni & Mn & Mo & B & Fe & V \\
\hline P1 & 0.19 & 18.83 & 1.14 & 1.54 & 0.45 & 0.91 & 1.13 & Bal. & 2.5 \\
P2 & 0.19 & 20.44 & 1.13 & 1.44 & 0.43 & 0.85 & 1.06 & Bal. & 4 \\
P3 & 0.20 & 22.24 & 1.13 & 1.31 & 0.39 & 0.77 & 0.96 & Bal. & 6 \\
P4 & 0.21 & 24.39 & 1.11 & 1.17 & 0.345 & 0.69 & 0.86 & Bal. & 8 \\
\hline
\end{tabular}

Table 3. Processing parameters of laser melt deposition (LMD).

\begin{tabular}{cc}
\hline Parameter & Values \\
\hline Laser power $(\mathrm{W})$ & 2200 \\
Scanning velocity $(\mathrm{mm} / \mathrm{min})$ & 480 \\
Powder feeding rate $(\mathrm{g} / \mathrm{min})$ & 12 \\
Shielding gas flux $(\mathrm{L} / \mathrm{h})$ & $400-500$ \\
Spot diameter $(\mathrm{mm})$ & 4 \\
Scanning interval $(\mathrm{mm})$ & 2 \\
Overlap $(\%)$ & 40 \\
\hline
\end{tabular}




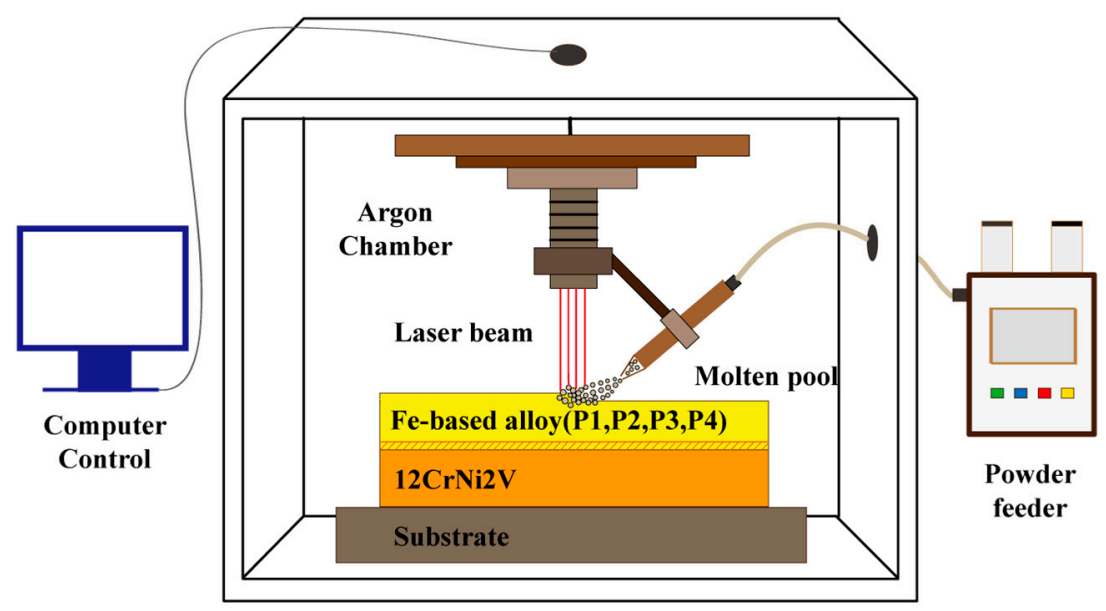

Figure 2. Schematic diagram of laser melting deposition process.

The phase constituent of gradient samples was identified using an X-ray diffractometer (XRD, XRD-7000, Rigaku, Tokyo, Japan) at a scanning speed of $4^{\circ} \mathrm{min}^{-1}$ range from $20^{\circ}$ to $100^{\circ}$, with $\mathrm{Cu}$ $\mathrm{K} \alpha$ radiation at $40 \mathrm{kV}$ and $35 \mathrm{~mA}$. The gradient sample was cut into $10 \times 10 \times 15 \mathrm{~mm}$ specimens by a wire electric discharge machine. After the gradient samples were ground down to 2000\# $\mathrm{SiC}$ abrasive paper, polished with $2.5 \mu \mathrm{m}$ diamond paste, washed, and dried, it was etched with $45 \mathrm{~mL} \mathrm{HCl}+15 \mathrm{~mL} \mathrm{HNO}_{3}+60 \mathrm{~mL}$ distilled water to wear-resistant Fe-based alloy and $2 \mathrm{~mL} \mathrm{HNO}_{3}+$ $48 \mathrm{~mL}$ alcohol to $12 \mathrm{CrNi2}$ for about $10 \mathrm{~s}$. The microstructure and chemical composition of the gradient samples were analyzed by scanning electron microscopy (SEM, S-3400N, Hitachi, Tokyo, Japan) and energy dispersive spectrometer (EDS, S-3400N, Hitachi, Tokyo, Japan) in the cross section of the gradient samples. The microhardness of the gradient samples was measured using a microhardness tester (HV, HVS-1000, Huayin, Laizhou, China) with a normal load of $2 \mathrm{~N}$ and a loading time of $10 \mathrm{~s}$. To ensure the accuracy of the data, the average values of three points measured at the same depth were taken as the microhardness values in the vertical section of the gradient samples. Friction and wear tests were carried out by wear tester (MFT-4000, Lanzhou Huahui Instrument Techonology Co., Ltd., Lanzhou, China) in the cross section of the gradient samples. The $\mathrm{Si}_{3} \mathrm{~N}_{4}$ ball with diameter $5 \mathrm{~mm}$ was used as friction pair with normal load of $15 \mathrm{~N}$, sliding velocity of $120 \mathrm{~mm} / \mathrm{min}$, the stroke length of $7 \mathrm{~mm}$, and friction time of $60 \mathrm{~min}$. The profile, wear volume, and specific wear rate of wear tracks were measured by surface profilometer (Micro XAM-3D, KLA-Tencor Corporation, Shanghai, China).

\section{Results and Analysis}

\subsection{Constituent Phase}

Figure 3 shows the XRD spectra of Fe-based alloy gradient materials. It is observed that the $12 \mathrm{CrNi2V}$ low alloy steel was composed of $\alpha$-Fe single phase solid solution (Figure 3a), while the wear-resistant Fe-based alloys were composed of $\alpha$-Fe matrix phase and different carbide hard phases (Figure 3b). The strong diffraction peaks of the crystal face (1 110$),\left(\begin{array}{lll}2 & 0 & 0\end{array}\right),\left(\begin{array}{lll}2 & 1 & 1\end{array}\right)$, and (2 20$)$ of $\alpha$-Fe can be identified [24]. The same matrix phase can form a better transition, avoiding the problem of greater internal stress caused by the combination of dissimilar phase structures [25]. S1, S2, and S3 were composed of $\alpha-\mathrm{Fe}, \mathrm{Cr}_{23} \mathrm{C}_{6}$, and $\mathrm{V}_{2} \mathrm{C}$. When $\mathrm{Cr}_{3} \mathrm{C}_{2}$ and FeV50 continued to increase, $\mathrm{V}_{2} \mathrm{C}$ changed to $\mathrm{V}_{8} \mathrm{C}_{7}$. Due to the rapid cooling rate of the molten pool, the $\mathrm{Cr}$ and $\mathrm{V}$ of the molten pool cannot be homogenized, resulting in the formation of $\mathrm{V}_{2} \mathrm{C}$ phase in $\mathrm{S} 1, \mathrm{~S} 2$, and S3. With the increase of $\mathrm{Cr}_{3} \mathrm{C}_{2}$ and FeV50 content, the carbon content increased. It made vanadium carbide more inclined to transition to more stable high-carbon vanadium compounds. The vanadium-carbon ratio in vanadium carbide changed from 2:1 to 8:7, resulting in the formation of $\mathrm{V}_{8} \mathrm{C}_{7}$ phase in $S 4$. Wang et al. [26] studied possible chemical reactions in molten pools and changes in standard Gibbs free energy. The results showed that 
$\mathrm{V}_{8} \mathrm{C}_{7}$ was heterogeneous nucleation center, and $\mathrm{Cr}_{7} \mathrm{C}_{3}$ with lower melting point was attached to $\mathrm{V}_{8} \mathrm{C}_{7}$ with higher melting point $\left(2810^{\circ} \mathrm{C}\right.$ [27]). It has been shown that the primary carbides in high-carbon Cr-based alloys were $(\mathrm{Cr}, \mathrm{Fe})_{23} \mathrm{C}_{6}$ and $(\mathrm{Cr}, \mathrm{Fe})_{7} \mathrm{C}_{3}$ with hexagonal structure [28]. $\mathrm{For} \mathrm{Cr}_{23} \mathrm{C}_{6}$ and $\mathrm{Cr}_{7} \mathrm{C}_{3}$ with orthogonal structure, the Gibbs free energy of $\mathrm{Cr}_{23} \mathrm{C}_{6}$ was lower [26]. For chromium carbide, the orthogonal structure was more stable than the hexagonal structure when the concentration of Fe was more than 40 at. \%. With the increase of $\mathrm{Cr}$ content, carbides tended to be stable, indicating that $\mathrm{Cr}_{23} \mathrm{C}_{6}$ was more feasibly formed and stable [29].
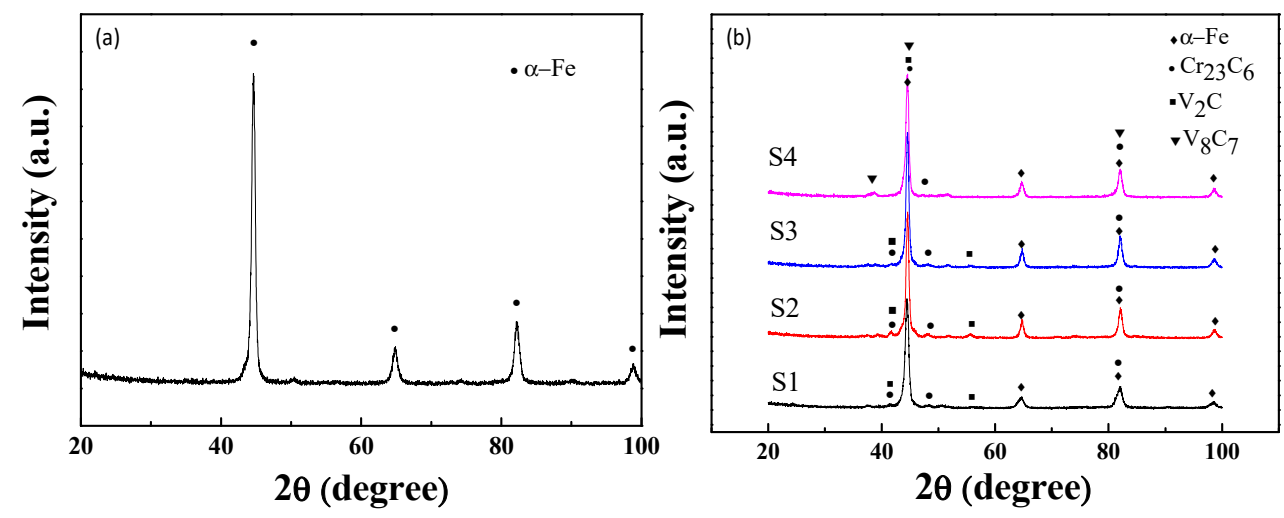

Figure 3. X-ray diffraction spectra of Fe-based alloy gradient materials by LMD (a) 12CrNi2V low alloy steel; (b) wear-resistant Fe-based alloys.

\subsection{Microstructure}

Figure 4 shows the cross section of the laser melting deposited Fe-based alloy gradient materials at low magnification. It can be observed that the laser melting deposited Fe-based alloy has shallow metallurgical bonding fusion line. There are also no holes, cracks, or other defects, indicating that a satisfied metallurgical bonding.
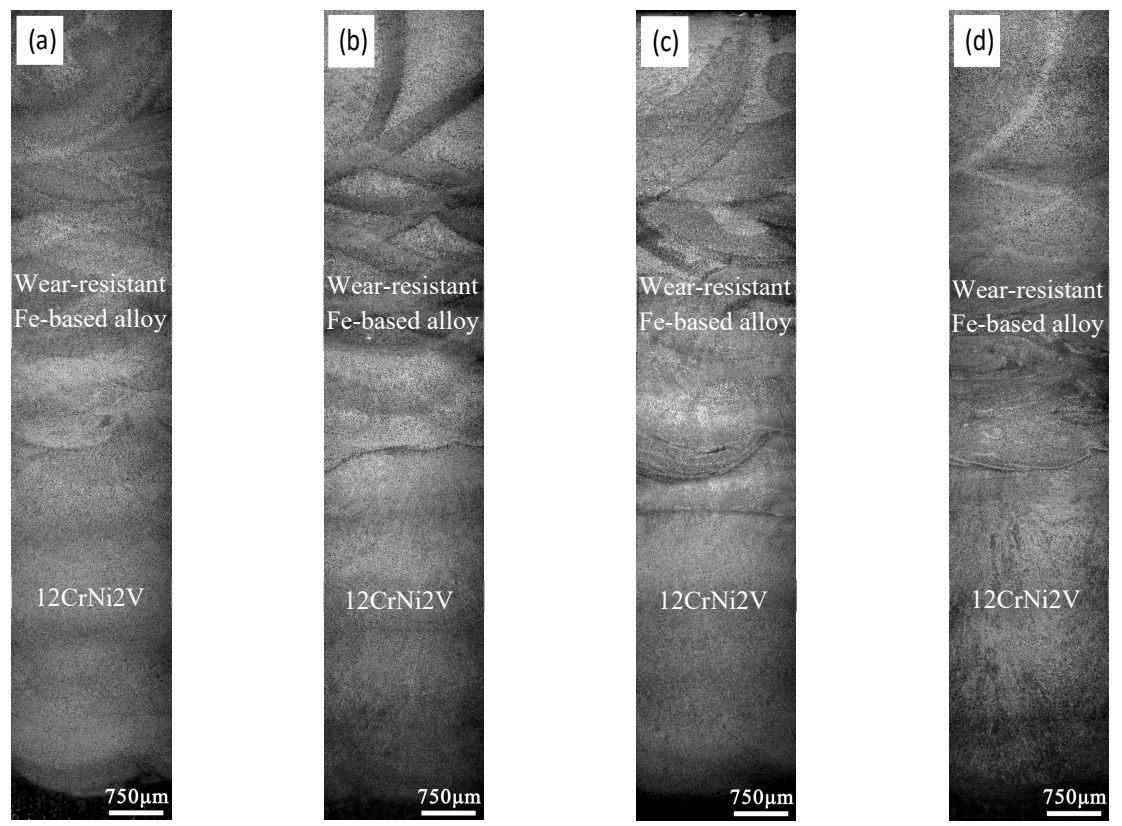

Figure 4. Cross section of the laser melting deposited Fe-based alloy gradient materials at low magnification (a) S1; (b) S2; (c) S3; (d) S4.

Figure 5 shows the cross-sectional SEM view of gradient materials by LMD. It can be observed that the microstructure of S1, S2, S3, and S4 was composed of cellular dendrite and intergranular structure, 
and a large number of white particles were dispersed inside the cellular dendrite, and a small amount of black particle existed in the intergranular structure (Figure 5a-d). The grain size of cellular dendrite in S2 decreased slightly, the grain size of cellular dendrite in S3 was more uniform, and the content of carbide particles in S4 increased noticeably. In the process of LMD, the alloy powder absorbed laser energy to melt and rapidly solidify. During the subsequent solidification, the primary phase carbides were precipitated in the liquid phase when the multicomponent alloy was cooled to the liquidus temperature [30,31]. The primary phase carbides grew freely in all directions. However, the growth of primary phase carbides was restricted because of the small diffusion coefficients of $\mathrm{Cr}$ and $\mathrm{V}$ elements in Fe-based alloys. Therefore, these carbides were dispersed in the form of fine particles in wear-resistant Fe-based alloys. In the process of LMD, carbides with high melting point took the lead in nucleation, which provided the adherence place of heterogeneous nucleation for the rear nucleation, and increased the nucleation density in Fe-based alloys [32]. The repeated irradiation of the laser beam in the process of LMD resulted in the precipitation of $C$ element in the form of carbides, and the formation of stable carbides by combining with strong carbide forming elements, which resulted in the reduction of the internal grain boundary energy. The migration of grain boundaries become more difficult, thus reducing the grain size of cellular dendrites. At the same time, with the increase of $\mathrm{Cr}_{3} \mathrm{C}_{2}$ and FeV50, the content of alloy elements in the external wear-resistant Fe-based alloy increased. Due to the limited solubility of the alloy elements in the cellular dendrite, a large number of alloy elements existed in the intergranular structure. The addition of Fe element can better form solid solution of the matrix, $\mathrm{Cr}, \mathrm{V}$, and $\mathrm{C}$ elements can be added to form carbides, these carbides were used as the second phase to reinforce the properties of materials. The microstructure and properties of Fe-VC composites by laser cladding have been studied by Zhang [33]. The results showed that the average microhardness of the cladding layer was $900 \mathrm{HV}$, which was five times higher than that of the matrix. The microstructure and mechanical properties of the Fe-Cr matrix composites prepared by hot pressing have been studied by Somunkiran et al. [34]. The results showed that the lowest average microhardness of Fe-Cr alloy was $218 \mathrm{HV}$ and the highest average microhardness was $261 \mathrm{HV}$. It can be seen that the effect of vanadium carbides on properties was better than chromium carbides. The microstructure of 12CrNi2V low alloy steel was a rapid directional solidification structure composed of coarse dendrite and intergranular structure (Figure 5e). The existence of intergranular structure was due to the high cooling rate in the liquid phase. The solidification microstructure was composed of ferrite matrix and martensite. Lath martensite was distributed on ferrite matrix, in which lath martensite consisted of lath beams with different directions. It can be seen that from the $12 \mathrm{CrNi} 2 \mathrm{~V}$ low alloy steel to the wear-resistant Fe-based alloy, the grain size gradually decreased with a gradient distribution (Figure 5f). The main components near the S3 interface (the region of the rectangular marks in Figure 5f) were analyzed, as shown in Figure 6. The results show that the contents of $\mathrm{Cr}$ and $\mathrm{V}$ elements decreased gradually, and the content of Fe element increased steadily from the wear-resistant Fe-based alloy to the $12 \mathrm{CrNi2V}$ low alloy steel. During the process of LMD, the surface temperature of $12 \mathrm{CrNi2}$ low alloy steel was raised and melted again by laser beam irradiation, and the liquid low alloy steel in the molten pool was diluted with the newly melted Fe-based alloy powder. The diffusion of alloying elements occurred, and then solidification formed a diffusion zone, which made the composition of the material gradient change. 

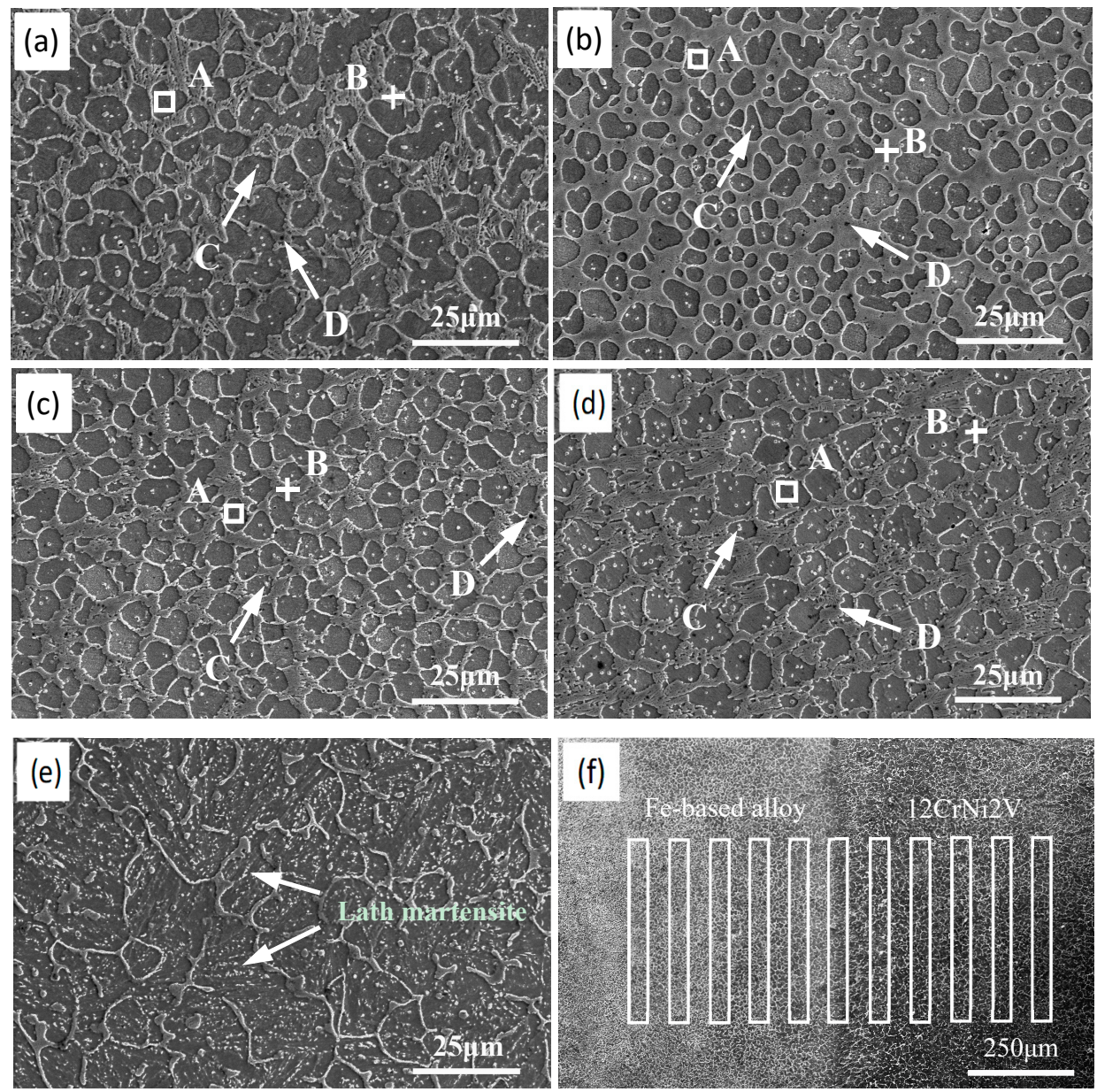

Figure 5. SEM images of the microstructures and interface of the laser melting deposited Fe-based alloy gradient materials (a) S1; (b) S2; (c) S3; (d) S4; (e) 12CrNi2V; (f) interface.

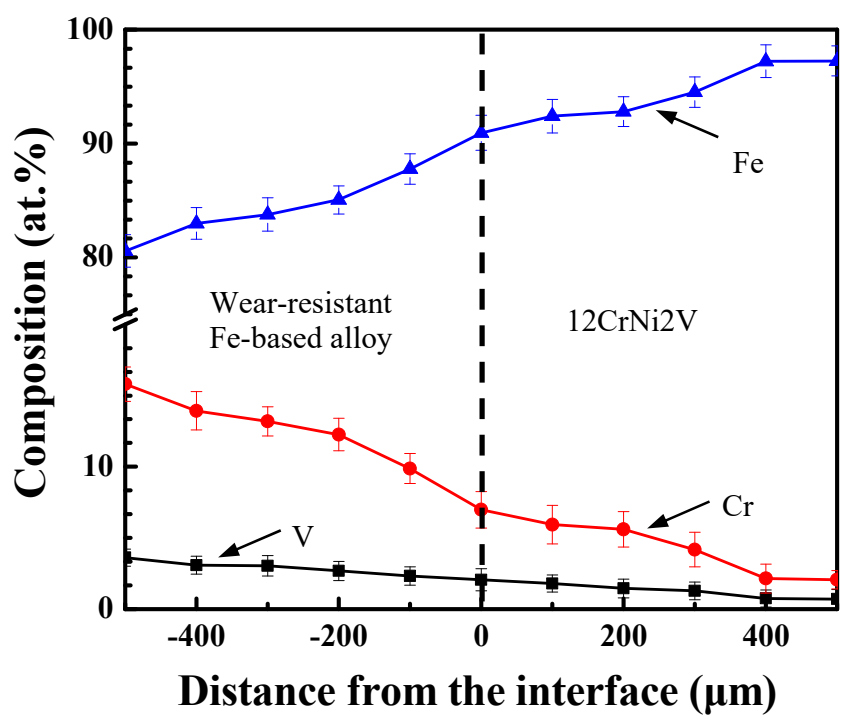

Figure 6. Composition near the interface of the laser melting deposited Fe-based alloy gradient materials.

To further understand the distribution of the alloy elements in the gradient materials and the influence of the alloy elements on the microstructure, the energy spectrum analysis of the different regions of the wear-resistant Fe-based alloy was carried out. The results of the analysis are shown 
in Tables 4 and 5. It can be seen from the region $\mathrm{A}$ and region $\mathrm{B}$ that the content of $\mathrm{Cr}$ and $\mathrm{V}$ in the dendrite was almost unchanged with the change of the powder composition. The content of $\mathrm{Cr}$ and $\mathrm{V}$ in the interdendritic region was significantly changed with the change of the powder composition. In the dendrite, the alloy elements were in a saturated state. With the increase of $\mathrm{Cr}_{3} \mathrm{C}_{2}$ and FeV50, the cellular dendrites in saturated state could not continue to solidify the alloying elements, which led to the increase of alloy elements in the interdendritic region with the change of powder composition. According to Table 5 , the contents of $C$ and $C r$ elements in region $C$ were relatively high. While, the region $\mathrm{D}$ was rich in $\mathrm{C}$ and $\mathrm{V}$ elements. Combined with $\mathrm{XRD}$ analysis, it can be inferred that the region $\mathrm{C}$ was $\mathrm{Cr}_{23} \mathrm{C}_{6}$, and the region $\mathrm{D}$ was $\mathrm{V}_{2} \mathrm{C}$ or $\mathrm{V}_{8} \mathrm{C}_{7}$.

Table 4. Content of main alloy elements in regions A and B of wear-resistant Fe-based alloys on the outside of gradient materials.

\begin{tabular}{ccccccccc}
\hline \multirow{2}{*}{ Sample Number } & \multicolumn{3}{c}{ Region A (wt. \%) } & \multicolumn{4}{c}{ Region B (wt. \%) } \\
\cline { 2 - 9 } & C & Cr & V & Fe & C & Cr & V & Fe \\
\hline S1 & 1.30 & 7.71 & 1.24 & 80.39 & 2.00 & 12.25 & 1.91 & 81.30 \\
S2 & 1.41 & 7.49 & 1.21 & 86.96 & 2.35 & 14.21 & 2.54 & 79.25 \\
S3 & 1.30 & 7.90 & 1.30 & 86.95 & 2.34 & 14.79 & 3.18 & 79.43 \\
S4 & 1.16 & 8.30 & 1.28 & 87.03 & 2.41 & 16.26 & 3.38 & 78.37 \\
\hline
\end{tabular}

Table 5. Content of main alloy elements in regions C and D of wear-resistant Fe-based alloys on the outside of gradient materials.

\begin{tabular}{ccccccccc}
\hline \multirow{2}{*}{ Sample Number } & \multicolumn{3}{c}{ Region C (wt. \%) } & \multicolumn{4}{c}{ Region D (wt. \%) } \\
\cline { 2 - 9 } & C & Cr & V & Fe & C & Cr & V & Fe \\
\hline S1 & 6.27 & 24.43 & 2.54 & 65.20 & 5.70 & 21.41 & 35.53 & 35.07 \\
S2 & 5.63 & 30.97 & 1.65 & 59.31 & 4.31 & 20.00 & 14.70 & 58.60 \\
S3 & 5.99 & 39.77 & 2.57 & 50.65 & 4.92 & 17.71 & 26.79 & 42.38 \\
S4 & 6.48 & 39.25 & 1.99 & 50.24 & 3.43 & 24.44 & 20.10 & 50.25 \\
\hline
\end{tabular}

\subsection{Microhardness}

Figure 7 shows the average microhardness of Fe-based alloy gradient materials prepared by LMD. The average microhardness of $12 \mathrm{CrNi} 2 \mathrm{~V}$ was about $325 \pm 30 \mathrm{HV}$. The average microhardness for S1, S2, S3, and S4 was $738 \pm 22,781 \pm 16,822 \pm 12$, and $853 \pm 18 \mathrm{HV}$, respectively. It can be seen that the surface microhardness of gradient materials was significantly improved. S4 was about 2.6 times of that of $12 \mathrm{CrNi2}$. The high microhardness can be attributed to the formation of the second phase particles (such as $\mathrm{V}_{2} \mathrm{C}, \mathrm{V}_{8} \mathrm{C}_{7}$, and $\mathrm{Cr}_{23} \mathrm{C}_{6}$ ), which acted as a reinforcing phase. The second phase also provided the position for the heterogeneous nucleation, increased the grain number, and caused the grain refinement and grain boundary strengthening [35]. In addition, during the manufacture of gradient samples, the solubility of alloy elements in dendrite increased due to the rapid cooling rate of the molten pool [36]. With the increase of C, $\mathrm{Cr}$, and $\mathrm{V}$, the lattice distortion in the laser-deposited-layer was increased, thus the solution effect of the alloy elements was further strengthened, and the microhardness of the gradient samples was improved. The $\mathrm{V}_{2} \mathrm{C}$ and $\mathrm{V}_{8} \mathrm{C}_{7}$ ceramic-reinforced Fe substrate surface compound layers were studied by Cai et al. [37]. The results showed that the hardness of $\mathrm{V}_{2} \mathrm{C}$ and $\mathrm{V}_{8} \mathrm{C}_{7}$ layers was $22.16 \pm 0.52$ and $32.42 \pm 0.61 \mathrm{GPa}$, respectively. Therefore, the formation of $\mathrm{V}_{8} \mathrm{C}_{7}$ was also an important factor in the improvement of hardness. 


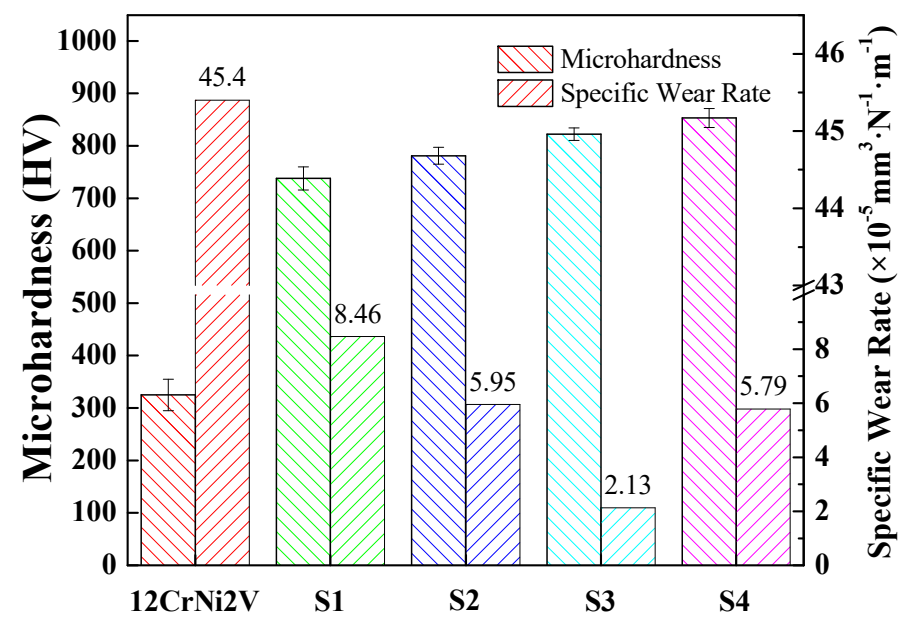

Figure 7. Microhardness curves and specific wear rates of Fe-based alloy gradient materials.

Figure 8 shows the microhardness profile of Fe-based alloy gradient materials. The microhardness of Fe-based alloy gradient material was a gradient distribution with the increase of deposition height. After the second gradient deposition of the wear-resistant Fe-based alloy powder, the 12CrNi2V low alloy steel was melted by the laser beam and permeated with the wear-resistant Fe-based alloy powder in the molten state. As a result, the content of alloying elements in the transition zone increased gradually along the direction of deposition, and the microhardness of the transition zone increased gradually. The reported literature shows that the fracture toughness is low when the microhardness is high, and the material is prone to embrittlement generally [38]. Houdková et al. [39] believed that the fracture toughness of the coating can be analyzed by the absence or presence of cracks around the Vickers indentation. It can be seen from Figure 8 that there are no cracks around the indentation, which qualitatively suggests a tough state of the Fe-based alloy gradient materials. The appropriate compromise between microhardness and fracture toughness indicates the practical application of the Fe-based gradient materials by LMD.

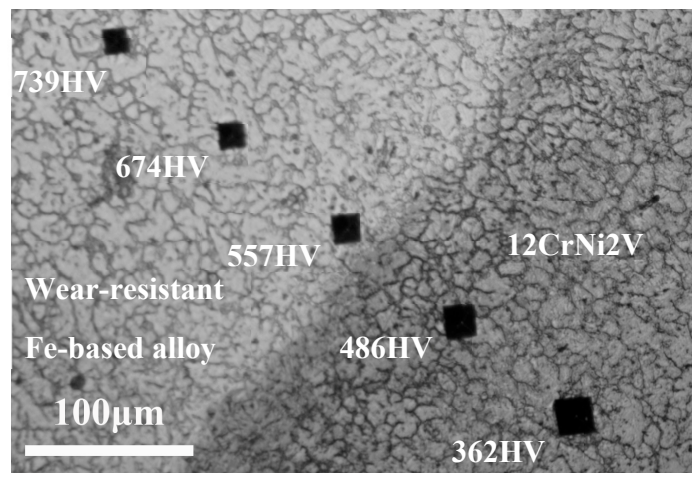

Figure 8. Microhardness profile along the melt depth of the laser melting deposited Fe-based alloy gradient materials.

\subsection{Wear Resistance}

By measuring the specific wear rate to characterize the wear resistance of the gradient sample, it can be expressed as [40]:

$$
\text { Specific wear rate }=V /(F L) \text {, }
$$

where $V, F$, and $L$ stand for wear volume, normal load, and sliding distance, respectively. Table 6 shows the wear volume of the laser melting deposited Fe-based alloy gradient materials. Figure 7 shows the specific wear rate of the Fe-based alloy gradient materials. Under the same wear conditions, the smaller 
the specific wear rate value, the better the wear resistance. As can be detected from the table, the specific wear rate of $12 \mathrm{CrNi2V}$ was the highest, about $4.54 \times 10^{-4} \mathrm{~mm}^{3} \cdot \mathrm{N}^{-1} \cdot \mathrm{m}^{-1}$. The specific wear rate of S3 was the lowest, about $2.13 \times 10^{-5} \mathrm{~mm}^{3} \cdot \mathrm{N}^{-1} \cdot \mathrm{m}^{-1}$. The specific wear rate of $\mathrm{S} 3$ was about 21 times better than 12CrNi2V. Zhang et al. [41] prepared Fe-Ti-V-Cr-C-CeO ${ }_{2}$ Fe-based composite coating by laser cladding. The wear resistance of the cladding layer was significantly improved, which was about 16.85 times than that of the substrate.

Table 6. Wear volume of the laser melting deposited Fe-based alloy gradient materials.

\begin{tabular}{cccccc}
\hline Sample Number & $\mathbf{1 2 C r N i 2 V}$ & S1 & S2 & S3 & S4 \\
\hline Wear Volume $\left(\mu \mathrm{m}^{3}\right)$ & $4.096 \times 10^{7}$ & $9.134 \times 10^{6}$ & $6.431 \times 10^{6}$ & $2.303 \times 10^{6}$ & $6.249 \times 10^{6}$ \\
\hline
\end{tabular}

To illustrate the wear mechanism of the gradient samples, the worn surfaces are characterized by SEM, as shown in Figure 9. It can be observed that the worn surface of S1 has more serious wear spalling (Figure 9a). There were a lot of white oxide particles in the spalling pit, and the worn surface near the spalling pit has a typical furrow caused by abrasive wear. During friction and wear, the surface of $\mathrm{S} 1$ was oxidized after heating up by friction. Under the normal stress and shear stress, oxide particles were formed by the oxide spalling. These oxide particles remained in the slide, causing damage to the surface of S1 under the extrusion of the upper friction pair. Therefore, the wear mechanism of S1 was oxidation and abrasive wear. The surface wear scar morphology of S2 changed significantly, and the wear spalling was alleviated (Figure 9b). The surface can be seen with obvious white oxide particles and furrows caused by abrasive wear. Combined with the microhardness curve of the gradient materials, the average microhardness of S2 was improved. The higher microhardness can reduce the cutting effect of the abrasive particles on the surface of the material, thus enhancing the friction and wear properties of the material. The wear mechanism of S2 was oxidation and abrasive wear. The worn surface of S3 was the same as S2, but the wear spalling was significantly reduced (Figure 9c). With the increase of microhardness, the ability of S3 to resist cutting effect was further improved. At the same time, there were some carbide particles distributed in the S3. In the process of friction and wear, these carbide particles came into contact with abrasive particles, effectively preventing abrasive particles from making an impression. Therefore, the abrasive particles were flattened or even broken, resulting in the reduction of the cutting ability of the abrasive particles [42]. The worn surface of S4 changed apparently, with visible signs of plastic flow and adhesion. There were also white oxides (Figure 9d). It showed that the wear mechanism was oxidative wear and adhesive wear. Although the microhardness of S4 was the highest, large particles will be formed due to the agglomeration of carbides in S4. In the dry sliding wear test, these large particles peel off the surface of the material. Large particles were attached to the wear ball, resulting in greater wear on the surface as the wear ball moved. At the same time, it also led to more contact between the upper friction pair and the surface. The local temperature at the surface contact point was very high, and the microhardness near these points decreased rapidly, resulting in plastic deformation. Fernández et al. [43] studied the effect of WC content on the reciprocating wear of NiCrBSi alloy reinforced by laser cladding with WC. The mismatch between hardness and wear resistance was also observed. From the above analysis, it can be seen that the wear resistance of S3 was the highest, but not the highest microhardness in gradient materials. This indicated that microhardness was not the only factor that affected wear resistance. The improvement of wear resistance could be achieved by proper combination of high microhardness and toughness [44]. As shown in Figure 9e, there were more oxide particles and clear plastic flow and adhesion on the worn surface of $12 \mathrm{CrNi} 2 \mathrm{~V}$ low alloy steel. It was indicated that the temperature of the contact points was high during sliding wear test, which resulted in a rapid decrease of the microhardness near the contact points [45]. Under the combined effect of normal stress and shear stress, the surface of low alloy steel was prone to plastic deformation. Therefore, the worn surface of $12 \mathrm{CrNi2}$ resulted in a higher wear volume loss. The wear mechanism of $12 \mathrm{CrNi2} \mathrm{V}$ was oxidation and adhesion wear. 

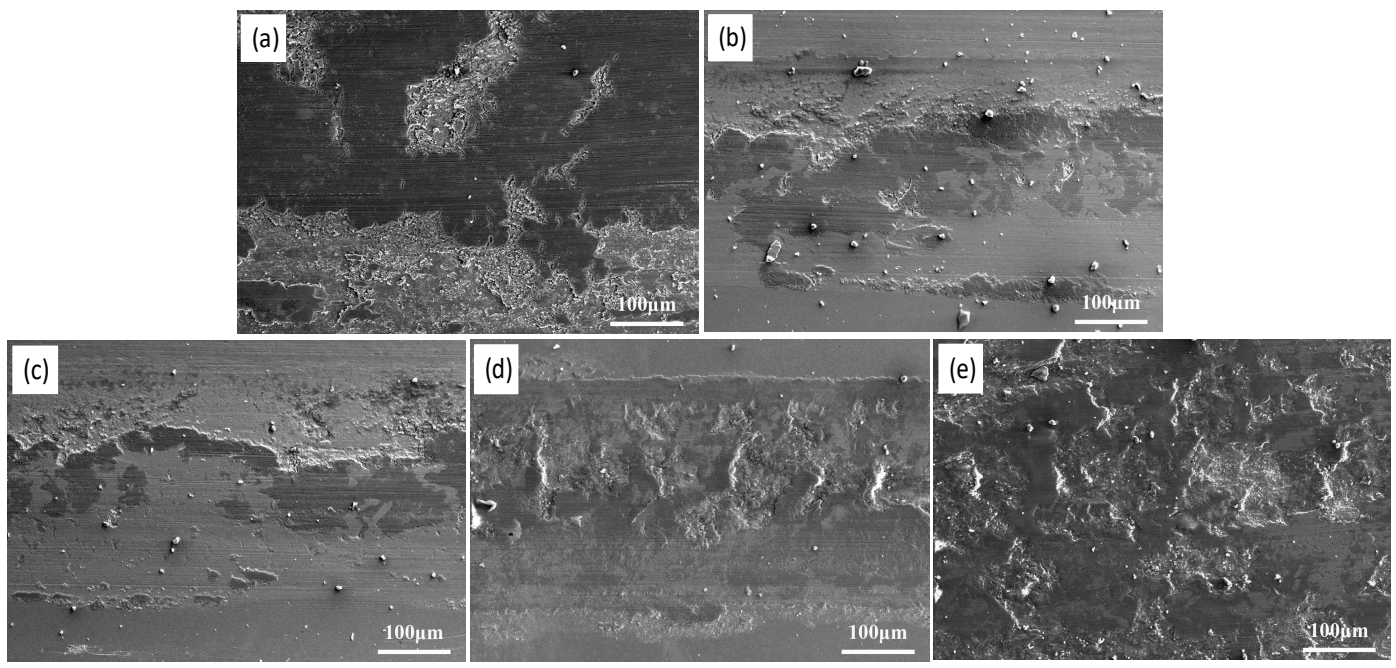

Figure 9. SEM micrographs of worn surface of the laser melting deposited Fe-based alloy gradient materials (a) S1; (b) S2; (c) S3; (d) S4; (e) 12CrNi2V.

Figure 10 shows the friction coefficient curves of Fe-based alloy gradient materials by LMD (Figure 10a) and typical cross-sectional profiles of the wear tracks (Figure 10b). It can be observed from Figure 10a that the friction coefficient curve of S1 and S2 still fluctuate irregularly after a period of running-in. It can be seen from the wear morphology that spalling occurred on the surface of S1 and S2. In the process of friction and wear, the number of abrasive particles in the slide increased. However, with the reciprocating motion of the upper friction pair, some abrasive particles were discharged out of the slide. Therefore, in the process of reciprocating wear, the number of abrasive particles changes. As a result, the wear conditions between the upper friction pair and the sample were in an unstable state, which made the friction coefficient fluctuate irregularly. The friction coefficient curves of S3 and S4 were relatively stable. The dispersed carbide hard phase can resist abrasive particles, resulting in reduced abrasive cutting ability. Thus, the influence of abrasive particles on wear conditions was reduced. Therefore, the friction coefficient curves of S3 and S4 were more stable. The average friction coefficient of S3 was obviously reduced. The average friction coefficient of S1, S2, S3, and S4 were 0.52, 0.55, 0.39, and 0.52, respectively. The friction coefficient of $12 \mathrm{CrNi} 2 \mathrm{~V}$ low alloy steel was 0.627 . Figure $10 \mathrm{~b}$ displays the typical cross-sectional profiles. It was found that the 12CrNi2V low alloy steel had the significant wear depth, indicating that its wear resistance was the worst. With the increase of $\mathrm{Cr}_{3} \mathrm{C}_{2}$ and FeV50, the wear depth of Fe-based alloys decreased gradually and then increased, which was consistent with the results of wear volume and specific wear rate. The wear depth of S3 was the lowest. This may attribute to the fact that the V element had a significant effect on grain refinement, which directly led to an increase in the number of grain boundaries. The zigzag grain boundaries can effectively prevent the occurrence of wear spalling and increase the ability to resist wear [23]. Additionally, the carbides reinforced in $\mathrm{S} 3\left(\mathrm{Cr}_{23} \mathrm{C}_{6}\right.$ and $\left.\mathrm{V}_{2} \mathrm{C}\right)$ were finely dispersed, and the interaction between these uniformly distributed second phases and dislocations hindered the dislocation movement. Thus, this led to the improvement in the deformation resistance of the wear-resistant Fe-based alloys [46]. Therefore, the wear resistance of S3 was enhanced by the combination of fine grain strengthening and second phase strengthening. 

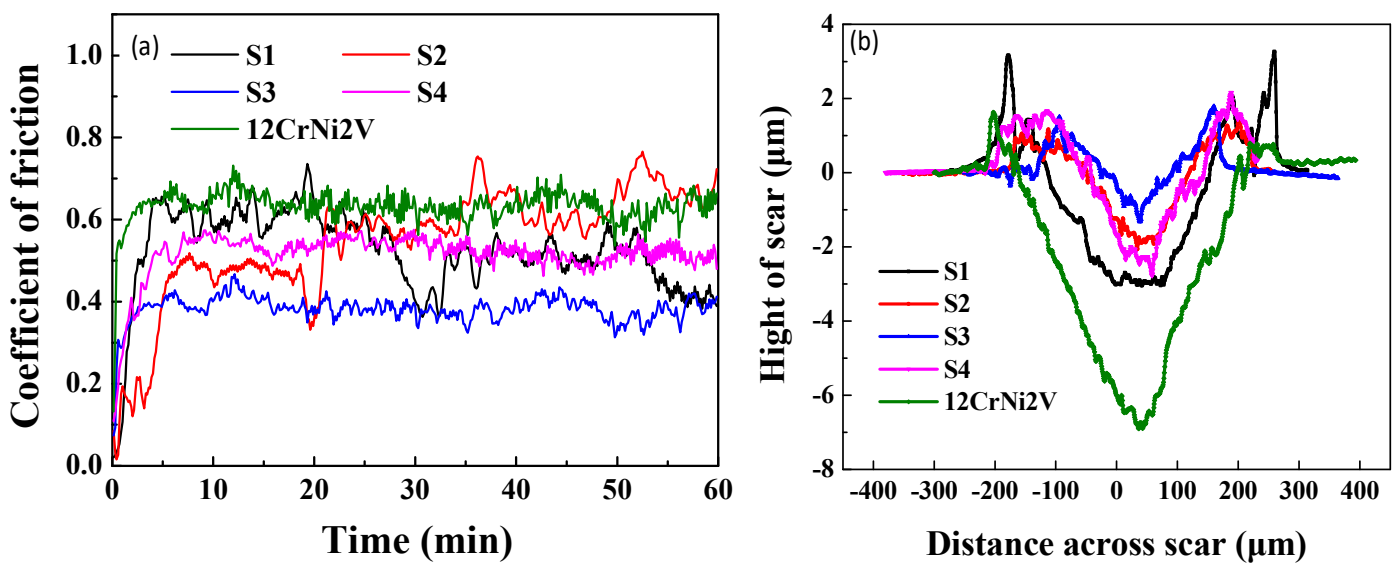

Figure 10. The friction coefficient curves of Fe-based alloy gradient materials (a) and typical cross-sectional profiles of the wear tracks $(\mathbf{b})$.

\section{Conclusions}

(1) To obtain the camshaft with surface rigidity and core toughness, the wear-resistant Fe-based alloy gradient materials were successfully prepared by LMD. The gradient materials satisfied formability and metallurgical bonding between $12 \mathrm{CrNi2} \mathrm{V}$ low alloy steel and wear-resistant Fe-based alloy.

(2) The microstructure of Fe-based gradient materials was mainly cellular dendrite and intergranular structure. The $12 \mathrm{CrNi} 2 \mathrm{~V}$ low alloy steel was composed of $\alpha$-Fe single phase solid solution, and $\mathrm{S} 1$, S2, and S3 were comprised of $\alpha-\mathrm{Fe}, \mathrm{Cr}_{23} \mathrm{C}_{6}$, and $\mathrm{V}_{2} \mathrm{C}$. With the increase of $\mathrm{Cr}_{3} \mathrm{C}_{2}$ and FeV50, the carbides of $\mathrm{S} 4$ vanadium changed from $\mathrm{V}_{2} \mathrm{C}$ to $\mathrm{V}_{8} \mathrm{C}_{7}$.

(3) With the increase of $\mathrm{Cr}_{3} \mathrm{C}_{2}$ and FeV50, the microhardness and wear resistance of Fe-based gradient materials were significantly better than that of $12 \mathrm{CrNi2V}$. The average microhardness of $\mathrm{S} 4$ was 2.6 times higher than that of $12 \mathrm{CrNi} 2 \mathrm{~V}$, and the wear resistance of $\mathrm{S} 3$ was about 21 times better than that of $12 \mathrm{CrNi2V}$. The wear mechanism of S1, S2, and S3 was oxidation wear and abrasive wear, while the wear mechanism of $\mathrm{S} 4$ and $12 \mathrm{CrNi} 2 \mathrm{~V}$ low alloy steel was oxidation wear and adhesive wear.

Author Contributions: W.Z. performed the experiments and wrote the manuscript; S.Z. designed the experimental process; J.Z. analyzed the data; C.W. assisted in SEM analysis; Y.L. assisted in microhardness analysis; A.O.A. assisted in paper review; C.Z. guided the direction of the research.

Funding: This research was funded by National Key Research and Development Program of China (No.2016YFB1100204), Key Research Project from Science and Technology Commission of Liaoning Province (Nos. 2017106036 and 2018106004), and Shenyang Science and Technology Funded Project (Nos. Z18-5-012, 18-004-1-16 and 18-201-0-02).

Conflicts of Interest: The authors declare no conflict of interest.

\section{References}

1. Lin, D.Y.; Hou, B.J.; Lan, C.C. A balancing cam mechanism for minimizing the torque fluctuation of engine camshafts. Mech. Mach. Theory 2017, 108, 160-175. [CrossRef]

2. Guan, T.T.; Chen, S.Y.; Chen, X.T.; Liang, J.; Liu, C.S.; Wang, M. Effect of laser incident energy on microstructures and mechanical properties of 12CrNi2Y alloy steel by direct laser deposition. J. Mater. Sci. Technol. 2019, 35, 395-402. [CrossRef]

3. Cui, X.; Zhang, S.; Zhang, C.H.; Wu, C.L.; Zhang, J.B.; Liu, Y.; Abdullah, A.O. Effect of powder oxygen content on formability of $12 \mathrm{CrNi} 2$ alloy steel fabricated by laser melting deposition. Powder Metall. 2019, 62, 186-195. [CrossRef] 
4. Rudnev, V.I.; Loveless, D. Induction hardening: Technology, process design, and computer modeling. Compre. Mater. Process. 2014, 12, 489-580.

5. Carroll, B.E.; Otis, R.A.; Borgonia, J.P.; Suh, J.O.; Dillon, R.P.; Shapiro, A.A.; Hofmann, D.C.; Liu, Z.K.; Beese, A.M. Functionally graded material of 304L stainless steel and inconel 625 fabricated by directed energy deposition: Characterization and thermodynamic modeling. Acta Mater. 2016, 108, 46-54. [CrossRef]

6. Chen, X.C.; Zhang, X.L.; Lu, Y.X.; Li, Y.H. Static and dynamic analysis of the postbuckling of bi-directional functionally graded material microbeams. Int. J. Mech. Sci. 2019, 151, 424-443. [CrossRef]

7. Zhang, Y.; Cheng, Z.Q.; Feng, H. Dynamic fracture analysis of functional gradient material coating based on the peridynamic method. Coatings 2019, 9, 62. [CrossRef]

8. Han, C.J.; Li, Y.; Wang, Q.; Cai, D.S.; Wei, Q.S.; Yang, L.; Wen, S.F.; Liu, J.; Shi, Y.S. Titanium/hydroxyapatite (Ti/HA) gradient materials with quasi-continuous ratios fabricated by SLM: Material interface and fracture toughness. Mater. Des. 2018, 141, 256-266. [CrossRef]

9. Chen, Y.; Zhang, J.Y.; Wang, B.; Yao, C.G. Comparative study of IN600 superalloy produced by two powder metallurgy technologies: Argon Atomizing and Plasma Rotating Electrode Process. Vacuum 2018, 156, 302-309. [CrossRef]

10. Li, X.; Peng, X.Y.; Dong, H.; Zhou, Y.; Wang, T.; Ren, K.; Sun, L. The evaluation of durability of plasma-sprayed thermal barrier coatings with double-layer bond coat. Coatings 2019, 9, 241. [CrossRef]

11. Pan, C.G.; Liu, D.D.; Zhao, C.X.; Chang, Q.M.; He, P. Corrosion and thermal fatigue behaviors of TiC/Ni composite coating by self-propagating high-temperature synthesis in molten aluminum alloy. Coatings 2017, 7, 203. [CrossRef]

12. Patel, B.; Pati, R.K.; Mukhopadhyay, I.; Ray, A. Effect of vacuum and sulphur annealing on the structural properties of spray deposited $\mathrm{Cu}_{2} \mathrm{SnS}_{3}$ thin films. Vacuum 2018, 158, 263-270. [CrossRef]

13. Ren, H.S.; Liu, D.; Tang, H.B.; Tian, X.J.; Zhu, Y.Y.; Wang, H.M. Microstructure and mechanical properties of a graded structural material. Mater. Sci. Eng. A 2014, 611, 362-369. [CrossRef]

14. Gualtieri, T.; Bandyopadhyay, A. Additive manufacturing of compositionally gradient metal-ceramic structures: Stainless steel to vanadium carbide. Mater. Des. 2018, 139, 419-428. [CrossRef]

15. Zhang, H.; Zhang, C.H.; Wang, Q.; Wu, C.L.; Zhang, S.; Chen, J.; Abdullah, A.O. Effect of Ni content on stainless steel fabricated by laser melting deposition. Opt. Laser Technol. 2018, 101, 363-371. [CrossRef]

16. Cortina, M.; Arrizubieta, J.I.; Ukar, E.; Lamikiz, A. Analysis of the influence of the use of cutting fluid in hybrid processes of machining and laser metal deposition (LMD). Coatings 2018, 8, 61. [CrossRef]

17. Chen, X.Y.; Yan, L.; Karnati, S.; Zhang, Y.L.; Liou, F. Fabrication and characterization of $\mathrm{Al}_{x} \mathrm{CoFeNiCu}_{1-x}$ high entropy alloys by laser metal deposition. Coatings 2017, 7, 47. [CrossRef]

18. Arcella, F.G.; Froes, F.H. Producing titanium aerospace components from powder using laser forming. JOM 2000, 52, 28-30. [CrossRef]

19. Qi, H.; Azer, M.; Singh, P. Adaptive tool path deposition method for laser net shape manufacturing and repair of turbine compressor airfoils. Int. J. Adv. Manuf. Technol. 2010, 48, 121-131. [CrossRef]

20. Qu, H.P.; Li, P.; Zhang, S.Q.; Li, A.; Wang, H.M. Microstructure and mechanical property of laser melting deposition (LMD) Ti/TiAl structural gradient material. Mater. Des. 2010, 31, 574-582. [CrossRef]

21. Zhang, C.H.; Zhang, H.; Wu, C.L.; Zhang, S.; Sun, Z.L.; Dong, S.Y. Multi-layer functional graded stainless steel fabricated by laser melting deposition. Vacuum 2017, 141, 181-187. [CrossRef]

22. Li, W.; Karnati, S.; Kriewall, C.; Liou, F.; Newkirk, J.; Taminger, K.M.B.; Seufzer, W.J. Fabrication and characterization of a functionally graded material from Ti-6Al-4V to SS316 by laser metal deposition. Addit. Manuf. 2017, 14, 95-104. [CrossRef]

23. Liu, Y.; Liang, C.P.; Liu, W.S.; Ma, Y.Z.; Liu, C.; Zhang, C. Dilution of Al and V through laser powder deposition enables a continuously compositionally Ti/Ti6Al4V graded structure. J. Alloys Compd. 2018, 763, 376-383. [CrossRef]

24. Zhou, Y.; Chen, S.Y.; Chen, X.T.; Cui, T.; Liang, J.; Liu, C.S. The evolution of bainite and mechanical properties of direct laser deposition $12 \mathrm{CrNi2}$ alloy steel at different laser power. Mater. Sci. Eng. A 2019, 742, 150-161. [CrossRef]

25. Hosseini, M.; Shishesaz, M.; Tahan, K.N.; Hadi, A. Stress analysis of rotating nano-disks of variable thickness made of functionally graded materials. Int. J. Eng. Sci. 2016, 109, 29-53. [CrossRef]

26. Wang, C.; Zhang, S.; Zhang, C.H.; Wu, C.L.; Zhang, J.B.; Abdullah, A.O. Phase evolution and wear resistance of in situ synthesized $\mathrm{V}_{8} \mathrm{C}_{7}$ particles reinforced Fe-based coating by laser cladding. Opt. Laser Technol. 2018, 105, 58-65. [CrossRef] 
27. Zhao, Z.W. Synthesis of $\mathrm{V}_{8} \mathrm{C}_{7}-\mathrm{Cr}_{3} \mathrm{C}_{2}$ nanocomposite via a novel in-situ precursor method. Int. J. Refract Met. Hard Mater. 2016, 56, 118-122. [CrossRef]

28. Lin, C.M.; Chang, C.M.; Chen, J.H.; Wu, W. Hardness, toughness and cracking systems of primary $(\mathrm{Cr}$, $\mathrm{Fe})_{23} \mathrm{C}_{6}$ and $(\mathrm{Cr}, \mathrm{Fe})_{7} \mathrm{C}_{3}$ carbides in high-carbon Cr-based alloys by indentation. Mater. Sci. Eng. A 2010, 527, 5038-5043. [CrossRef]

29. Sobolev, A.; Mirzoev, A. Structure and stability of $(\mathrm{Cr}, \mathrm{Fe})_{7} \mathrm{C}_{3}$ ternary carbides in solid and liquid state. J. Alloys Compd. 2019, 804, 566-572. [CrossRef]

30. Wang, H.Y.; Zhang, S.; Zhang, C.H.; Wu, C.L.; Zhang, J.B.; Abdullah, A.O. Effects of V and Cr on laser cladded Fe-Based coatings. Coatings 2018, 8, 107. [CrossRef]

31. Flint, T.F.; Panwisawas, C.; Sovani, Y.; Smith, M.C.; Basoalto, H.C. Prediction of grain structure evolution during rapid solidification of high energy density beam induced re-melting. Mater. Des. 2018, 147, $200-210$. [CrossRef]

32. Khalili, A.; Goodarzi, M.; Mojtahedi, M.; Torkamany, M.J. Solidification microstructure of in-situ laser-synthesized Fe-TiC hard coating. Surf. Coat. Technol. 2016, 307, 747-752. [CrossRef]

33. Zhang, W. Research on microstructure and property of TiC-Co composite material made by laser cladding. Appl. Laser 2012, 25, 205-208. [CrossRef]

34. Somunkiran, I.; Buytoz, S.; Dagdelen, F. Determination of curie temperatures and thermal oxidation behavior of Fe-Cr matrix composites produced by hot pressing. J. Alloys Compd. 2019, 777, 302-308. [CrossRef]

35. Tam, K.F.; Cheng, F.T.; Man, H.C. Cavitation erosion behavior of laser-clad Ni-Cr-Fe-WC on brass. Mater. Res. Bull. 2002, 37, 1341-1351. [CrossRef]

36. Chen, C.J.; Wang, M.C.; Wang, D.S.; Jin, R.; Liu, Y.M. Laser cladding of Mg20A180 powder on ZM5 magnesium alloy. Brit. Corros. J. 2007, 42, 130-136. [CrossRef]

37. Cai, X.L.; Zhong, L.S.; Xu, Y.H.; Lu, Z.X.; Li, J.L.; Zhu, J.L.; Ding, Y.C.; Yan, H.H. Microstructural characterization of a $\mathrm{V}_{2} \mathrm{C}$ and $\mathrm{V}_{8} \mathrm{C}_{7}$ ceramic-reinforced Fe substrate surface compound layer by EBSD and TEM. J. Alloys Compd. 2018, 747, 8-20. [CrossRef]

38. Wu, C.L.; Zhang, S.; Zhang, C.H.; Zhang, H.; Dong, S.Y. Phase evolution and cavitation erosion-corrosion behavior of FeCoCrAlNiTix high entropy alloy coatings on 304 stainless steel by laser surface alloying. J. Alloys Compd. 2017, 698, 761-770. [CrossRef]

39. Houdková, Š.; Zahálka, F.; Kašparová, M. Fracture toughness of HVOF sprayed cermet coatings measured by vickers indentation. Key Eng. Mater. 2011, 465, 475-478. [CrossRef]

40. Wu, C.L.; Zhang, S.; Zhang, C.H.; Zhang, H.; Dong, S.Y. Phase evolution and properties in laser surface alloying of FeCoCrAlCuNi ${ }_{x}$, high-entropy alloy on copper substrate. Surf. Coat. Technol. 2017, 315, 368-376. [CrossRef]

41. Zhang, H.; Zou, Y.; Zou, Z.D.; Wu, D.T. Microstructure and properties of Fe-based composite coating by laser cladding Fe-Ti-V-Cr-C-CeO 2 powder. Opt. Laser Technol. 2015, 65, 119-125. [CrossRef]

42. Bi, J.; Lei, Z.L.; Chen, X.; Li, P.; Lu, N.N.; Chen, Y.B. Microstructure and mechanical properties of TiB ${ }_{2}$-reinforced 7075 aluminum matrix composites fabricated by laser melting deposition. Ceram. Int. 2019, 45, 5680-5692.

43. Fernández, M.R.; García, A.; Cuetos, J.M.; González, R.; Noriega, A.; Cadenas, M. Effect of actual WC content on the reciprocating wear of a laser cladding NiCrBSi alloy reinforced with WC. Wear 2015, 324-325, 80-89. [CrossRef]

44. Hu, H.J.; Huang, W.J. Studies on wears of ultrafinegrained ceramic tool and common ceramic tool during hard turning using Archard wear model. Int. J. Adv. Manuf. Technol. 2013, 69, 31-39. [CrossRef]

45. Zhong, M.L.; Jiang, D.F.; Zhang, H.J.; Hong, C.; Weisheit, A.; Kelbassa, I. Fabrication of nanoparticulate reinforced metal matrix composites by laser cladding. J. Laser Appl. 2014, 26, 022007. [CrossRef]

46. Li, S.N.; Xiong, H.P.; Li, N.; Chen, B.Q.; Gao, C.; Zou, W.J.; Ren, H.S. Mechanical properties and formation mechanism of $\mathrm{Ti} / \mathrm{SiC}$ system gradient materials fabricated by in-situ reaction laser cladding. Ceram. Int. 2017, 43, 961-967. [CrossRef]

(C) 2019 by the authors. Licensee MDPI, Basel, Switzerland. This article is an open access article distributed under the terms and conditions of the Creative Commons Attribution (CC BY) license (http://creativecommons.org/licenses/by/4.0/). 